\title{
Los judíos de Toledo en el contexto de la ciudad
}

\author{
Ricardo IzQUierdo Benito *
}

Desde que Pilar León Tello, hace unos años, publicara su voluminosa monografía sobre los judíos de Toledo ${ }^{1}$, poco es ya lo nuevo que se pueda decir sobre esta comunidad. Sin embargo, no por ello hay que pensar que su historia está ya cerrada, pues muchos aspectos de la misma pueden ser precisados o recapitulados, tomando como referencia la propia documentación recogida en la citada obra o los datos extraídos de otras fuentes complementarias. Es con este planteamiento con el que abordamos la elaboración del tema de esta exposición que ahora nos ocupa y que va a versar sobre las relaciones que los judíos toledanos mantuvieron con los demás habitantes cristianos de la ciudad, en general, y con algunas instituciones de ésta, en particular, a lo largo de la Edad Media.

Trataremos, por consiguiente, no de analizar el funcionamiento interno de la aljama de Toledo y las relaciones de convivencia entre sus propios miembros que, en la mayor parte de los casos quedarían reducidas a los estrictos límites de la judería y de sus barrios anejos, sino a aquéllas que, precisamente, trascienden estos límites y se proyectan hacia el resto del espacio ciudadano - especialmente hacia el sector mayoritario que podríamos denominar «cristiano»- estableciendo unos contactos y unas pautas de conducta que a lo largo de los siglos medievales se alteraron con bastante frecuencia. En definitiva, lo que pretendemos, fundamentalmente, es señalar cómo se desenvolvieron las relaciones entre unos to-

* Universidad de Castilla-La Mancha.

1 León Telıo, Pilar, Judíos de Toledo, 2 vols., CSIC. Madrid 1979. Desde ese año, no han sido muchas las publicaciones que, referentes al Toledo judío, han visto la luz. Entre las mismas citaremos la de Porres MARTiN-CLETo, Julio, «Algunas precisiones sobre las juderías toledanas», en Anales Toledanos, XVI, 1983, págs. 37-61 y la de BLÁzquez Miguel, Juan, Toledot. Historia del Toledo judío. Toledo 1989. 
ledanos, cristianos, y otros toledanos, judíos, en el marco estricto de la propia ciudad.

Por ello, no vamos a tener en cuenta las relaciones que algunos judíos toledanos mantuvieron con otros ámbitos, en los que llegaron a destacar, incluso considerablemente. Así, en el ámbito de la intelectualidad y de la cultura hispanojudía, no podemos olvidar figuras como Abu Harun Mosé ibn Abil Ais, Abu Zakkariya Yehudá, Ya aqob ben Eleazar, Todros ben Yehudá ha-Levi Bu-I-Afia, Ishac ben Zadof, etc., y en el más prosaico de las finanzas, en el entorno de la monarquía castellana, personajes como Yosef Ibn Salomón ibn Susan, Salomón ibn Zadok (don Çuleman), Todros ha-Levi ben Yosef abu-I-Afia, Abraham Barchilón, Samuel ha-Levi, etc. El desempeño de su actividad les llevó a otras esferas y a otros lugares, al margen de la propia ciudad, aunque, evidentemente, siempre quedaran vinculados a la judería toledana de la cual formaron parte y a la que prestigiaron.

Sin embargo, como ya he señalado, va a ser de otros judíos, más humildes - al menos en renombre- de los que me voy a ocupar, es decir, de aquéllos que permanecieron en la ciudad y que su medio de vida les llevó a entrar, inevitablemente, en contacto con el resto de la población, dado que era imposible vivir en un estado de aislamiento y máxime cuando unos y otros, mutuamente, se necesitaban. Destacar cómo fueron aquellas relaciones, en qué consistieron y por qué cauces atravesaron, es lo que ahora nos interesa.

No obstante, también queremos precisar que en el análisis de estas relaciones sólo vamos a tener en cuenta aquéllas que se establecieron entre judíos -en el sentido estricto del término-y el resto de la población de Toledo, por lo que no nos vamos a referir al sector social de los conversos, ya que éstos, al convertirse al cristianismo, consideramos que dejaron de ser judíos, aunque bien es cierto que en algunos casos permanecieron fieles a su antiguo credo religioso. Se trata, por consiguiente, de un contexto en el que las relaciones de convivencia adquieren otra dimensión, en verdad de gran interés y ya suficientemente conocida, pero que, consideramos, excede los límites del tema propuesta para abordar en esta exposición. Por lo cual, todos los conflictos referentes al fenómeno converso que se desarrollaron en la ciudad, especialmente durante el siglo XV, no los vamos a tener en consideración, a pesar de su indudable trascendencia. Nosotros nos vamos a ocupar, por tanto, de aquel grupo social que podemos considerar como genuinamente judío.

\section{INTRODUCCIÓN}

La primera presencia, al menos estable, de judíos en Toledo, parece remontarse al siglo $\mathrm{I}$, tras el reciente hallazgo de un fragmento de lucerna 
decorado con una «menoráh». Posiblemente no se trataría de una comunidad muy numerosa, pero iría paulatinamente incrementándose y adquiriendo cada vez más importancia, especialmente cuando la ciudad se convirtió en el centro político de la monarquía visigoda. Bien es cierto que sobre ella pudo haber recaído, de una manera más directa, la intransigencia antisemita que algunos monarcas visigodos aplicaron durante el siglo VII ${ }^{2}$.

No obstante, a pesar de todo, parece que la comunidad judía toledana no llegó a desaparecer, y con ella se encontraron los musulmanes en el momento que ocuparon la ciudad. Dada la tolerancia religiosa de éstos, los judíos permanecieron y se les asignó un espacio (la Madinat al-Yahud) - posiblemente el mismo que ya venían ocupando de antiguo-, que en el año 820 fue delimitado por una muralla, convirtiéndose así en la base territorial de lo que, en un proceso paulatino de expansión, configuraría la futura judería. Este recinto se encontraba en un extremo marginal de la ciudad, alejado del núcleo principal de la misma, en la parte occidental, sobre el Tajo. Junto a él, pronto debieron de concentrarse actividades molestas e insalubres (tenerías, alfares, mataderos, etc.), lo que remarcaría la sensación de aislamiento y de marginación, aunque algunos judíos llegaron a poseer tiendas en la ciudad. La convivencia con los musulmanes debió de ser pacífica pues al menos no se tienen noticias de posibles enfrentamientos.

Sin embargo, aquella situación se iba a alterar tras la ocupación de Toledo por Alfonso VI en 1085. La ciudad, tras casi cuatro siglos de ocupación islámica, volvía nuevamente a manos cristianas, en un momento de expansión de la cristiandad occidental, lo que habría de tener repercusiones en las relaciones con la población judía. El hecho significativo era que una comunidad judía resultaba "conquistada» por un ejército cristiano, aunque no se conocen las condiciones, si las hubo, en que aquélla habría de quedar tras la capitulación. Lo evidente es que los judíos, en un estado de sometimiento, quediaban inmersos en un contexto social cristiano, en el que el clima anterior de aparente pacífica convivencia se vería pronto alterado.

No obstante, los reyes castellano-leoneses necesitaban a los judíos, tanto por su simple condición de habitantes de un lugar - ante las dificultades por encontrar nuevos repobladores-como, especialmente, por la destacada preparación en actividades económicas que algunos tenían

\footnotetext{
2 Lacave Riaño, José Luis, "La legislación antijudía de los visigodos", en Simposio Toledo Judaico, vol. I, págs. 31-42.
} 
y por su conocimiento de la lengua árabe. Por lo cual, tuvieron que practicar una tolerancia hacia ellos, acogiéndoles incluso bajo su directa protección. Sin embargo, los judíos toledanos - al igual que los musulmanes que permanecieron en la ciudad-a diferencia de los demás sectores cristianos (castellanos, francos y mozárabes), no recibieron un fuero especial cuando se pusieron las bases jurídicas diferenciadoras para organizar aquel entramado social que se estaba configurando en la ciudad. Era el alcalde de los mozárabes el que servía de juez en las demandas que presentaban los judíos y los musulmanes a los cristianos. En el fuero de los mozárabes de 1101 se especificaba que éstos pagasen solamente la quinta parte de las caloñas en que incurriesen, excepto en los casos de hurto o muerte de judío o moro ${ }^{3}$. En la recopilación de los fueros de Toledo que realizó Alfonso VII en 1118, se señalaba que la muerte de un judío se juzgase según el Liber ludiciorum ${ }^{4}$.

Con estos planteamientos se iniciaba una larga etapa de forzada convivencia, que iba a durar otros cuatro siglos, a lo largo de los cuales las relaciones entre la comunidad judía y el sector cristiano dominante, atravesaron por muy diversos altibajos.

A lo largo del siglo xII la aljama toledana vería incrementado el número de sus efectivos, especialmente durante la segunda mitad, cuando muchos judíos huyeron de al-Andalus ante la intransigencia religiosa de los almohades. De esta manera, con estos refugiados, se fue constituyendo un grupo cada vez más numeroso e influyente, que contribuyó, en gran medida, al desarrollo económico de la ciudad, por la que algunos judíos tenían sus tiendas y talleres, así como sus casas, al no existir una obligación expresa de vivir en su propio barrio.

Aunque parecía existir un buen clima de convivencia con el resto de la población, en ocasiones debía de alterarse, como ocurrió en 1180, en que, víctima de un atentado popular, falleció Abraham ben David, considerado como el primer historiador hispano-hebreo. Sin embargo, en 1212 los toledanos se opusieron a los desmanes que contra los judíos estaban cometiendo las tropas francesas que se habían concentrado en la ciudad en vísperas de las Navas de Tolosa.

3 García Gallo, Alfonso, "Los fueros de Toledo", en Anuario de Historia del Derecho Español, XLV, 1975, págs. 459-461.

4 Idem, págs. 473-483. 
En el siglo xIII, la aljama de Toledo, que gozaba de una cierta autonomía en su organización, se había convertido en la más rica e influyente de la Corona de Castilla. Como los demás vecinos de la ciudad, los judíos eran de condición libre e igualados a los cristianos ante los tribunales de justicia. Podían adquirir y vender libremente propiedades y, como los demás ciudadanos, también contribuían a los gastos del municipio.

Por lo que respecta a las actividades que entonces desempeñaban, predominaba la agricultura y especialmente el cultivo de la vid. También existían algunos prestamistas aunque, por lo general, operaban con pequeñas cantidades. Otros se dedicaban a oficios muy diversos: carniceros, sastres, albañiles, molineros, etc. Incluso algunos mantenían relaciones comerciales con al-Andalus, dada la relativa proximidad de la frontera.

En aquella época algunos judíos toledanos desempeñaron cargos importantes en la Corte, como diplomáticos, médicos y, sobre todo, como recaudadores y arrendadores de rentas públicas, llegando a ocupar puestos de gran responsabilidad. Otros destacaron por su dedicación a la literatura, especialmente a la poesía. En este ámbito de la intelectualidad es de señalar la participación que algunos judíos debieron de tener en la traducción de muchas obras escritas en árabe, dentro del movimiento conocido como "Escuela de Traductores de Toledo".

Pero, aparte de esta minoría influyente - poseedora de grandes riquezas y honores - el resto de la comunidad judía vivía, de una manera más directa, inmersa en el contexto económico de la ciudad, que era el ámbito en el que verdaderamente se manifestaba la mayor parte de los contactos con el sector cristiano.

\section{CONTACTOS ECONÓMICOS}

A pesar de las indudables diferencias que existían entre los dos sectores -impuestas, fundamentalmente, por motivos religiosos- es evidente que no permanecían al margen uno del otro y que entraron en contacto, estableciendo unas relaciones de convivencia, aparentemente amistosas entre conciudadanos, aunque bien es cierto que, en ocasiones, se alteraron con resultados muchas veces trágicos.

Aparte de contactos más directos, rayanos en amistades personales, de los que, de haber existido, no ha quedado constancia en la documentación, y que son los que verdaderamente marcarían un clima de auténtica convivencia, es al nivel de las relaciones económicas donde mejor se reflejan los contactos entre judíos y el resto de la población cristiana. 
Muchos judíos tenían establecimientos comerciales --tiendas y mesones-, propios o alquilados, dispersos por la ciudad, especialmente por las zonas más marcadamente mercantiles, y a muchos de ellos, inevitablemente, tenía que acudir el sector cristiano para proveerse de las mercancías o productos necesarios. Estos locales, por tanto, se convertían en reductos en los que se manifestarían contactos personales, aunque fuesen simplemente al nivel de una sencilla compra cotidiana.

También fueron frecuentes las compras mutuas entre particulares, tanto de bienes urbanos, como, especialmente rústicos, y en los que, por parte cristiana, fue muy corriente que participasen personajes del estamento eclesiástico (capellanes, racioneros, canónigos, etc.) o establecimientos religiosos de la ciudad, tales como monasterios o conventos, e incluso la propia catedral como veremos más adelante ${ }^{5}$. Es muy posible que algunas de estas ventas tan frecuentes estuviesen encubriendo pagos de deudas, contraídas con anterioridad, y no satisfechas en los plazos estipulados.

Entre estas ventas, aunque no era muy frecuente, en ocasiones se vendían esclavos musulmanes. Así, por ejemplo, el 11 de enero de 1273, Martín García de Abra vendió al judío Abuomar, hijo del jeque Abusuleiman ben Abuomar ben Nehemías, un esclavo granadino llamado Mohamed ben Ibrahim el Cazloni, de oficio panadero, por 145 mizcales blancos ${ }^{6}$. Y el 21 de junio de 1313, Abraham, hijo de don Mayr el Leví, vendió a María Alfonso una mora blanca, manceba, llamada Mariam?

Sin embargo, en el campo en el que las relaciones económicas adquirieron mayor intensidad -al menos en algunos momentos - fue en el de los préstamos y la usura, referente al cual se ha conservado una documentación abundante y significativa, que nos permite conocer cómo se desenvolvió esta actividad y la intensidad que llegó a alcanzar, a pesar de la prohibición religiosa - bíblica y talmúdica- que los judíos tenían para ejercer la usura ${ }^{8}$. Los documentos no recogen el interés a abonar,

5 En la obra de González Palencia, Angel, Los mozárabes de Toledo en los siglos xil y xiI, 4 vols. Madrid 1930, son muchos los ejemplos en este sentido que se pueden constatar.

${ }^{6}$ Archivo Histórico Nacional (en adelante citado AHN), clero, pergaminos, carpeta 3.063, n. 013 .

7 Idem, carpeta $3.026, n \cdot{ }^{\circ} 11$.

- Nosotros no vamos a entrar a elaborar un análisis profundo sobre el tema de la usura judía, en general, ya muy conocido por otra parte (usura encubierta, deudas impagadas, solicitud en Cortes de moratorias o anulación de deudas, etc.), ni sobre la usura en Toledo, en particular. Lo que aquí nos interesa destacar es que la práctica de esta actividad suponía el establecimiento de unas relaciones entre el sector cristiano y el judío, tema este que es el que ahora nos ocupa. 
pero se procuraba garantizar la devolución del préstamo en plazos cortos y generalmente con medidas coercitivas. Todo ello va a suponer que una parte del sector cristiano caiga en una dependencia económica de los judíos y va a ser el germen de enfrentamientos y conflictos que alterará las relaciones de convivencia, especialmente en los momentos de recesión económica. De ahí los frecuentes intentos por parte de la población afectada - reflejados en las actas de Cortes de la época-, por conseguir anulaciones, rebajas o moratorias en el pago de las deudas contraídas.

Ya a finales del siglo XII se señalan prestamistas judíos en Toledo, aunque, por lo general, aportando cantidades no muy elevadas. Era frecuente que los deudores, sobre todo cuando se trataba de campesinos, acabasen perdiendo sus tierras al no poder saldar la deuda en los plazos fijados ${ }^{9}$.

En los primeros años del siglo XIII se observa un cierto incremento en el número de prestamistas judíos, que aumentará considerablemente en la segunda mitad de esa centuria, durante los reinados de Alfonso $X$ y Sancho IV. Como ha señalado Pilar León Tello, el mayor porcentaje de los judíos toledanos vivía de los préstamos, siendo pocos los que en esta época se dedicaron a la agricultura o a la artesanía ${ }^{10}$. Varias familias toledanas se encuentran empeñadas con prestamistas judíos y muchos deudores tienen que malvender sus bienes para satisfacer sus deudas, especialmente gentes de condición modesta.

El 14 de febrero de 1290, Sancho IV mandó que se quitase en Toledo el entregador que él mismo había puesto para las deudas de los judíos, y que los problemas relacionados con éstas se resolviesen ante los alcaldes de la ciudad, como había sido siempre costumbre ${ }^{11}$.

Todavía durante la primera mitad del siglo xIV la actividad prestamista es la que sigue predominando entre los judíos toledanos. Sin embargo, la crisis económica que iba a caracterizar a aquella centuria, iba a repercutir muy directamente en este punto, pues la devolución de los préstamos se hacía cada vez más difícil, lo que suponía que los judíos también se podían arruinar. De ahí las constantes peticiones que, en Cortes, se hicieron entonces para anular todas las deudas 0 , al menos, para conseguir alguna moratoria en su pago. Sin embargo, la monarquía no estaba

\footnotetext{
León Tello, P., op. cit., I, pág. 43.

Idem, pág. 79.

11 IzQUiERo Benito, Ricardo, Privilegios reales otorgados a Toledo durante la Edad Media (1101-1494). Toledo 1990. doc. n. ${ }^{\circ} 41$.
} 
dispuesta a ceder y perjudicar a los judíos, por lo que se resistió a aceptar las reiteradas demandas ${ }^{12}$.

Alfonso XI, no obstante, accedió a conceder una moratoria de menos de dos años en el pago de las deudas - que vencía el 1 de septiembre de 1347- durante cuyo plazo no se pagarían intereses. Sin embargo, el 2 de enero de aquel año, los judíos toledanos consiguieron del rey que se les exceptuase de aquella disposición, pues alegaron que en Toledo, una vez vencido el plazo de las pagas, no ganaban más que las novenas. Al enterarse de esta concesión, y dado el gran volumen que las deudas alcanzaban en la ciudad, ésta envió a sus procuradores a Ciudad Real, donde se encontraban los judíos que la habían conseguido y parece que les convencieron para tratar el asunto de una manera amistosa. Llegaron al acuerdo de que los préstamos, cuyos plazos hubiesen cumplido antes del 1 de noviembre, se pagarían por cuartas partes, en los meses de febrero, agosto y noviembre de 1347 y enero de 1348. Si en el primer plazo no se pagaba la cuantía de lo estipulado más las novenas, se perdía la gracia de este acuerdo y los alcaldes tendrían facultad para entregar, en los bienes del deudor, la cuantía de la deuda con los correspondientes beneficios $^{13}$.

Siempre según Pilar León Tello, la actividad de prestamistas era casi inherente a los judíos toledanos. No solamente estaban dedicados al préstamo las familias más linajudas y los comerciantes más acaudalados, sino modestos artesanos que, en cuanto reunían algún dinero, lo empleaban para dar a logro ${ }^{14}$.

Sin embargo, esta actividad decreció considerablemente durante la segunda mitad del siglo xIV (Ordenamiento de Alcalá de 1348 suprimiendo la usura, Peste Negra, guerra civil de Pedro I y Enrique de Trastámara, acontecimientos de 1391 , etc.) y a lo largo del siglo xV, momentos en los que también el número de judíos fue en descenso, repercutiendo todo ello en su declive económico y social.

No obstante, aunque la mayor parte de los préstamos era de los judíos hacia ios cristianos, también se conocen algunos casos a la inversa, aunque no debieron de ser muy frecuentes. Así, por ejemplo, en 1163, el caid

\footnotetext{
12 A la monarquía no le interesaba el empobrecimiento o la ruina de los judíos, pues éstos debían de seguir manteniendo su capacidad fiscal, para que pagasen tanto los impuestos indirectos como los tributos especiales a que estaban obligados.

${ }^{13}$ Archivo Municipal de Toledo (en adelante citado AMT), cajón $5 .^{\circ}$, leg. $7 .^{\circ}$ LEón TELLO, P., op. cit., I, doc. 33 .

14 León Tello, P., op. cit., I, pág. 126.
} 
don Pelayo Petrus prestó al judío toledano Ishac ben Abiyusef, 170 mizcales de oro ${ }^{15}$; en 1209, doña Loba, hija del alguacil y alcalde don Esteban Julianes, prestó 50 mizcales de oro alfonsí al judío Ishac y a su esposa Chamila ${ }^{16}$; y en 1489 , los Reyes Católicos dieron un plazo para el pago de sus deudas a don Yuça Bienveniste, a causa de algunas pérdidas que había tenido ${ }^{17}$.

Es curioso que, habiendo sido entonces Toledo uno de los centros industriales y mercantiles más importantes de la Corona castellana, eran muy pocos los judíos que se dedicaban a comerciar fuera de la ciudad. Sin embargo, a través de algunos ejemplos que, en realidad, también están vinculados con el tema de los préstamos, podemos conocer que se establecían relaciones entre judíos y cristianos, a modo de pequeñas sociedades, para participar en los beneficios de ciertos negocios mercantiles, que normalmente eran realizados por la parte judía. Así, el 16 de junio de 1294, el alguacil y alcalde don Juan García reclamó 3.000 mizcales que había entregado al judío Abusuleiman ben Abulhasan Salih ben Alcahil, para que con ellos comerciase durante un año en telas, paños y otras mercancías, con la condición que de las ganancias le entregase las dos terceras partes ${ }^{18}$. $Y$ el 24 de abril de 1340, María Fernández entregó a Jacob Abencota y a su mujer Cinha, 1.000 maravedies para que traficasen en mercancía de paños y cera, con la condición de devolver esa cantidad y la mitad de las ganancias obtenidas, en el plazo de un año ${ }^{19}$.

Como parece deducirse, era en este amplio campo de los préstamos, con todo lo que ello conllevaba, en el que se manifestaban, de una manera más directa las relaciones entre los judíos y los cristianos de Toledo. Un campo muy resbaladizo, de equilibrios muy inestables que, inevitablemente, repercutían en otras facetas de la convivencia ciudadana.

\section{RELACIONES CON LA CATEDRAL}

Aunque, en principio, pudiera pensarse que, por considerarles como "enemigos religiosos", la catedral de Toledo, como máxima institución eclesiástica de la ciudad, habría mantenido una actitud de rechazo hacia

\footnotetext{
AHN, clero, pergaminos, carpeta 3.036, n. ${ }^{\circ}$ 5. LEÓN TELLO, P., op. cit., I, doc. 22. AHN, clero, pergaminos.

Simancas, Registro General del Sello, fol. 70. Lé́n TelLo, P., op. cit., I, doc. 80.

AHN, clero, pergaminos, carpeta $3.068, n .^{\circ} 17$.

19 Archivo del Monasterio de San Clemente de Toledo, carpeta 12, n. ${ }^{\circ}$ 19. León Tello, P.,
} op. cit., I, doc. 22. 
los judíos, ello no fue así, sino al contrario, pues también estableció con ellos relaciones, aunque casi siempre por motivaciones económicas, ya que, en definitiva, también les necesitaba. Los arzobispos toledanos y el cabildo de la catedral mantuvieron, en general, buenas relaciones con los judíos, a pesar de las disposiciones canónicas antisemitas que, con frecuencia, se promulgaban.

Ya a comienzos del siglo XIII, tras las medidas que contra los judíos se acordaron en el IV Concilio de Letrán -entre ellas una serie de impuestos y la obligación de llevar una señal distintiva- el arzobispo don Rodrigo Jiménez de Rada consideró oportuno no alterar sus ánimos, para evitar que emigrasen a otros países, y consiguió, con la intervención del propio rey Fernando III, que el papa Honorio III, el 19 de marzo de 1219, suprimiese en Castilla la aplicación de la medida del signo distintivo.

El mismo don Rodrigo ofreció a los judíos de Toledo, mediante una concordia que se llevó a cabo el 16 de junio de 1219, acogerles bajo su protección, a cambio de ciertas concesiones: los diezmos y ofrendas que debían entregar a la Iglesia, de acuerdo a lo establecido en el citado Concilio, se sustituirían por una cantidad fija - la sexta parte de un áureo- que todo judío varón pagaría al cabildo a partir de los 20 años o desde antes si contraía matrimonio; para garantizar el cumplimiento de este acuerdo, el arzobispo designaría a seis adelantados - cuatro de la aljama y dos de las sinagogas- para que, bajo juramento, declarasen el número de varones sujetos al pago; si algún judó vendía heredad a cristiano y después la quisiese volver a adquirir, no pagaría diezmo por ella, pero si quería comprar heredad de cristiano, sin antes haberla poseído, abonaría el diezmo con que estuviese gravada; la permuta de casas quedaba libre de tributos; a los viejos de las aljamas se les hacía responsables del cumplimiento del pago del impuesto general ${ }^{20}$.

Desde que, en 1086, Alfonso VI reinstaurara la sede toledana, la catedral empezó a constituir un extenso patrimonio, tanto rural como urbano, mediante donaciones y adquisiciones ${ }^{21}$. Muchas compras de bienes, especialmente rústicos, fueron efectuadas a judíos, a lo largo del siglo XII y a comienzos del XIII ${ }^{22}$. Para la explotación de este patrimonio, mediante contratos de arrendamiento, la catedral también recurrió, en ocasiones, a

20 Todos estos aspectos pueden verse en León Tello, P., op. cit., I, págs. 59-60.

21 Rivera Recio, Juan Francisco, La lglesia de Toledo en el siglo xil (1086-1208), vol. I. Roma 1966; vol. I1. Toledo 1976.

22 En la obra de GonzÁlez Palencia, Los mozárabes..., op. cit., son también muchos los ejemplos que a este respecto se pueden extraer. 
judíos. A lo largo de la Edad Media, fueron muchos los judíos que tuvieron arrendadas propiedades de la catedral, tanto en el campo como en la ciudad.

En Toledo, la catedral tenía un importante conjunto de edificios (casas, tiendas, mesones, hornos, etc.), algunos incluso dentro de la propia judería, muchos de los cuales estaban alquilados a familias judías. Evidentemente, de cara a conseguir la máxima rentabilidad de su patrimonio, y tratándose muy posiblemente de gente considerada como solvente, aquélla no tuvo inconveniente alguno en aceptar a judíos como usufructuarios de sus propiedades. En definitiva, de lo que se trataba era de que pagasen lo estipulado y a su debido tiempo.

De la misma manera, la catedral también recurrió a judíos de la ciudad y de pueblos de los alrededores, para que, mediante pujas previas, recaudasen rentas - sobre todo los diezmos-- de su extenso arzobispado ${ }^{23}$, así como para solicitarles préstamos - especialmente los arzobispos-cuando tenía que hacer frente a apuros económicos. De ahí que la propia Iglesia, como ya hemos señalado anteriormente, tambén se veía implicada en el tema de la usura en relación con los judíos, máxime cuando también, tanto los arzobispos como el cabildo, hicieron préstamos a éstos.

Algunos toledanos que habían conseguido cartas del papa Clemente $V$ contra la usura, acudían a las dignidades de la catedral para que éstas, bajo sentencia de excomunión, obligasen a los judíos a la devolución de los intereses que habían percibido en sus préstamos. Ante lo cual, la aljama de Toledo se quejó al rey Fernando IV, quien asumió la defensa de los judíos, encargando a Ferrant Yuanes Pantoja que recordase al cabildo que no estaba dispuesto a consentir que pusiese sentencia contra los judíos y se anulasen las que estuviesen puestas. Se amenazaba con encarcelar y proceder contra los bienes de los que desobedeciesen aquella orden. Con lo cual, los canónigos toledanos renunciaron a entrometerse en los pleitos relacionados con la usura de los judíos ${ }^{24}$.

Parece observarse que, en Toledo, desde mediados del siglo xIV y a lo largo del $\mathrm{XV}$, a la par que disminuye el número de judíos prestamistas, aumenta el de los que se dedicaban al arrendamiento de rentas, no sólo

23 Así se puede constatar en la serie de libros denominados «del Refitor», conservados en el archivo de Obra y Fábrica de la Catedral de Toledo (Torroja MEnÉndez, Carmen, Catálogo del Archivo de Obra y Fábrica de la Catedral de Toledo. Toledo 1977).

${ }^{24}$ BAER, Yitzhak, Historia de los judíos en la España Cristiana, vol. I. Madrid 1981, págs. 241-242. 
de la catedral, sino también de rentas reales, de otras instituciones eclesiásticas y de la propia ciudad ${ }^{25}$. No obstante, por lo que respecta a la catedral, parece que, a medida que avanza el siglo xv, y especialmente durante su segunda mitad, son cada vez menos los judíos que arriendan sus rentas. También se producian bastantes sentencias de excomunión por el impago de cantidades adeudadas.

Aparte de esta colaboración económica con los judíos, la catedral también mantuvo alguna relación más directa con alguno de ellos en particular, pues entre su personal casi siempre figuró algún médico judío, lo que suponía otorgarle una gran confianza, aunque bien es cierto que en aquella época esta profesión estaba prácticamente monopolizada por judíos y a ellos forzosamente había que recurrir.

El cabildo también tenía derecho a percibir ciertas rentas, que arrendaba, situadas sobre la judería de la ciudad ${ }^{26}$. Así, las denominadas «medio diezmo del vino de los judíos» y «las almaguanas de las carnicerías de los judíos» ${ }^{27}$. La cuantía de estas rentas no era fija, por lo que fluctuaba mucho cada año, tanto por la evolución de la producción agraria -especialmente en el caso de la primera ${ }^{28}$ - como por las variaciones demográficas, en el caso de la segunda ${ }^{29}$.

${ }_{25}$ Según Juan Blázquez Miguel, de unas 202 familias judías que, a finales del siglo xV vivían en Toledo, 56 eran arrendadoras de rentas, lo que suponía casi un 25 por 100 (Toledot..., op. cit., pág. 164).

26 Desde época de Alfonso X los judíos de Toledo daban cada año a la catedral 30 dineros, que le correspondían a él. Esta misma donación la concedió al cabildo de Sevilla con respecto a los judíos de aquella ciudad (León TELlo, P., op. cit, II, doc. 168).

27 Las "almaguanas» debían de corresponder a la cuarta parte de los tributos de las carnicerías de los judíos de Toledo, derecho que fue cedido al cabildo por don Suero, arzobispo de Santiago y anteriormente miembro de aquél. El 12 de septiembre de 1371, Enrique II confirmó esta donación ya que no se podía hacer a clérigos (GARCía LUJÁN, José Antonio, Privilegios reales de la catedral de Toledo (1086-1462), II, docs. 101 y 105. Toledo 1982).

En 1445 se debió de entablar un pleito entre la aljama y el cabildo por la percepción de las almaguanas y el 2 de octubre de 1450, el juez eclesiástico notificó a los representantes de aquella que pagasen todos los atrasos que debían o mil maravedís anuales, para lo que se les asignaba un plazo de tres días (LEÓN TELLO, P., op. cit, 1, doc. 55) .

28 Por ejemplo, el «medio diezmo del vino de los judíos» se arrendó en 1372 en 1.796 maravedís mientras que en 1379 sólo por $360 \mathrm{~m}$., fluctuación que parece estar en relación con un descenso de la producción agraria (IzQuIERdo Benito, Ricardo, El patrimonio del cabildo de la catedral de Toledo en el siglo XIV. Toledo 1980, pág. 279). Sin embargo, en la cuantía de esta renta también podía influir la variación en el número de contribuyentes. Así, en 1391, antes de los sucesos de aquel año, se había arrendado en $750 \mathrm{~m}$., mientras que en 1395 sólo por $40 \mathrm{~m}$. (IZQUIERdo Benito, Ricardo, «Repercusiones de una crisis y medidas para superarla. Toledo en el siglo xIV», en En la España Medieval (Homenaje al Prof. D. Claudio Sánchez-Albornoz), I, 1986, pág. 523, nota 22 .

${ }_{29}$ En 1452 , y posiblemente como un reflejo de la disminución de la población judía, el cabildo sustituyó la renta de las "almaguanas de las carnicerías de los judíos» por un censo de 150 maravedís en unas casas que en el Alacava le dio la aljama. 
El 13 de enero de 1285 Sancho IV concedió al arzobispo don Gonzalo García Gudiel, que en las villas de la Iglesia de Toledo no hubiese entregador que realizase las entregas de las deudas de los judíos y que esta misión estuviese encomendada a los alcaldes y aportellados que el arzobispo y el cabildo designasen ${ }^{30}$.

Aunque aquí nos hayamos referido exclusivamente a las relaciones que la catedral -arzobispos y cabildo-- mantuvieron con los judíos de Toledo, las mismas consideraciones se pueden aplicar a las demás instituciones religiosas de la ciudad, como los monasterios y los conventos ${ }^{31}$. Es decir, que el estamento eclesiástico, a pesar de todas las disposiciones canónicas que a lo largo de la Edad Media se promulgaron para limitar el contacto con los judíos, no tuvo inconveniente alguno en contar con la colaboración de éstos, aunque bien es cierto que a un nivel puramente económico. Era, evidentemente, aquél en el que no se podía prescindir de ellos, por lo que, cualquier prejuicio religioso quedaba al margen, tratándose de intereses económicos.

\section{CONVIVENCIA ALTERADA}

Hasta aquí hemos presentado un panorama que, aparentemente, podríamos considerar como de buena convivencia entre judíos y cristianos de Toledo. Sin embargo, esas relaciones, como ya se ha comprobado, se basaban casi exclusivamente en unos mutuos intereses económicos - especialmente en todo lo relativo a la usura - que, en realidad, era el germen de unas rivalidades que, en ocasiones, podían manifestarse de una manera violenta. Por eso, para mejor comprender el verdadero alcance de esa "convivencia", de la que ya hemos visto una faceta, es necesario conocer la otra, para así tener una visión más ajustada a la auténtica realidad de los hechos.

A pesar de haber estado bajo ia protección directa de la propia monarquía, los judíos de Toledo - al igual que todos los de la Corona de Castilla - se vieron afectados por todo un conjunto de disposiciones antisemitas - no siempre cumplidas también es cierto-dimanadas tanto de los poderes públicos (Cortes), como de los poderes religiosos (concilios,

\footnotetext{
AHN, Sellos, caja 6, n.․ 15. León Tello, P., op. cit., I, doc. 11.

31 Como ejemplo vid. el catálogo del Archivo del Monasterio de San Clemente (TorRoJA Menéndez, Carmen, Catálogo del Archivo del Monasterio de San Clemente de Toledo. Toledo 1974) a través del cual se podrá comprobar las relaciones económicas que la abadesa y monjas del mismo mantuvieron con judíos.
} 
sínodos). De ahí, por consiguiente, que existiesen trabas que tendían a hacer más dificultosas las relaciones de convivencia. Además, en Toledo - lo mismo que en otras ciudades castellanas-y desde el Ayuntamiento, en determinadas ocasiones se acordaron medidas contra los judíos, por lo que todavía se tendía a reforzar más, a nivel local, el estado de segregación en el que se encontraban.

Al estar basadas esas relaciones en unos intereses casi exclusivamente económicos, iban a estar muy directamente condicionadas por los vaivenes de la coyuntura económica y por los avatares de la evolución política. De manerra que las épocas de estabilidad política y económica, tendían a coincidir con momentos de tranquilidad en las relaciones, mientras que en los momentos de alteración de esta estabilidad, era cuando se intensificaban las medidas antijudías, llegándose, en ocasiones, a enfrentamientos violentos, con consecuencias trágicas, ya que el recurso más inmediato era echar la culpa a los judíos de todos los males que ocurrían.

Toledo, tanto por el significado de la propia ciudad en el contexto político de la Corona de Castilla, como por el de su judería dada la importancia que llegó a alcanzar, se convirtió en la Edad Media en uno de los escenarios que mejor dejaron de manifiesto esas desavenencias.

Como parece que, en general, ocurrió en Castilla, también en Toledo, durante los siglos XII y XIII, apenas se tienen noticias de enfrentamientos graves entre judíos y cristianos, salvo algunos casos esporádicos. Sin embargo, a lo largo de aquellos años - como ya hemos visto - las prácticas prestamistas adquirieron una gran intensidad, con lo que se estaban poniendo las bases de un enfrentamiento latente que podía salir a la superficie, violentamente, si la situación económica se agravaba y si sobre ella, además, incidían otros factores. Eso es lo que ocurrió en el siglo XIV, cuando la recesión económica de aquella centuria fue acompañada de una crisis política en la que los judíos se vieron inmersos y afectados por los sangrientos sucesos que entonces se desarrollaron.

En efecto, en Toledo, en el siglo xIv tuvieron lugar los acontecimientos más dramáticos (saqueos, matanzas, etc.) que originaron que su judería, muy afectada por los mismos, perdiera la preponderancia que hasta entonces había tenido sobre las demás de Castilla. En el siglo siguiente la violencia se dirigió hacia los conversos que, como resultado de los conflictos, empezaron a proliferar. Las disposiciones antijudías dimanadas de los poderes públicos fueron en aumento durante aquella centuria, como un goteo lento pero persistente, que acabó por desembocar en la ruptura definitiva. 
Un hecho significativo que debió de repercutir muy directamente sobre la judería toledana, aunque desconozcamos en qué grado afectó a sus relaciones con los cristianos, fue la propagación de la Peste Negra a mediados del siglo XIV. Las bajas causadas por la epidemia debieron de ser acusadas entre toda la población, en general, y entre la judía, en particular, como parece reflejarse a través de las inscripciones de varias lápidas funerarias del cementerio judío ${ }^{32}$. Muchos judíos, de todos los niveles sociales, debieron de perecer por efecto de la enfermedad, lo que repercutió en un descenso demográfico de la judería toledana y en un empobrecimiento de la misma. Dado que en el sector cristiano se produjo la misma situación, todo ello tuvo que repercutir, inevitablemente, en las relaciones entre ambos sectores, y especialmente en las relaciones económicas.

Especial trascendencia iba a tener en Toledo la guerra civil entre Pedro I y su hermanastro Enrique de Trastámara. La ciudad contaba con un gran tradición histórica, era sede primada de la Iglesia hispana, un importante centro económico y, además, contaba con una de las aljamas judías más poderosas de Castilla por su peso económico e intelectual. Pedro I apoyó y protegió a los judíos pues necesitaba contar con su colaboración para hacer frente a los apuros económicos de la Corona. Enrique, para restar partidarios a su rival, utilizó como arma política fácil —pero demasiado peligrosa- el antisemitismo popular, acrecentado, además, en un período de crisis generalizada como aquél. En Toledo vivían algunos de los más poderosos financieros judíos. Por todo ello, la judería toledana iba a pagar trágicamente las consecuencias.

Como acertadamente ha señalado Julio Valdeón, aquel acontecimiento bélico y sus secuelas, fueron decisivos en la historia de las relaciones entre la comunidad cristiana y la judía en el reino castellano, al producirse un cambio radical en la convivencia que hasta entonces habían mantenido ${ }^{33}$.

A raíz del confinamiento en Tcledo de doña Blanca de Borbón, mujer de Pedrol, en el verano de 1354, durante el mes de mayo del año siguiente tuvo lugar en la ciudad un enfrentamiento entre partidarios de ambas facciones, de resultas del cual el barrio judío del Alacava fue asaltado y saqueado por los trastamaristas - pereciendo bastantes judíosmientras que la judería principal pudo resistir al encontrarse amurallada. Poco después, en el mes de octubre, conseguida la pacificación de la

32 LEÓN TELLLO, P., op. cit., I, pág. 113.

33 Valdeón Baruque, Julio, "La judería toledana en la guerra civil de Pedro I y Enrique ll», en Simposio Toledo Judaico, I, págs. 107-108. 
ciudad, Pedro I concedió un perdón general a todos los que habían participado en los sucesos, del que excluyó a aquéllos más significados «que fisieron algunos malefiçios contra los dichos mios judíos, en la dicha judería, el dicho dia que yo entré en Toledo» ${ }^{34}$. Recientes todavía los estragos de la Peste Negra, la comunidad judía toledana quedaría muy mermada en sus efectivos humanos.

Un ejemplo de esta protección que Pedro I dispensó a los judíos, es el pago de 18.000 maravedíes que el Ayuntamiento de la ciudad, como entidad colectiva responsable, tuvo que entregar para la cámara del rey, por la muerte de tres judíos en el término de Toledo, al no haber podido detener y entregar a los culpables del crimen. El 13 de diciembre de 1358 fue necesario vender un mesón de paños para pagar esa cantidad ${ }^{35}$.

En 1366 Enrique de Trastámara penetró en Castilla desde Aragón con tropas mercenarias francesas y, tras proclamarse rey en Burgos, se dirigió a Toledo, donde exigió a los judíos de la ciudad que, en un plazo de 15 días, le entregasen un millón de maravedíes para pagar a dichas tropas. Dado lo elevado de esa cantidad, y aunque no se pagase en su totalidad, lo cierto es que esta medida tuvo que suponer una considerable sangría económica para la judería toledana, máxime en un momento de recesión demográfica.

Aprovechando la presencia del pretendiente en la ciudad, el 11 de mayo de aquel año, los representantes de ésta le presentaron una serier de peticiones - recogidas en un cuaderno ${ }^{36}$ - a través de las cuales se puede constatar la situación de crisis económica por la que atravesaba Toledo en aquellos momentos ${ }^{37}$. Entre otras, le pidieron la supresión de todas las deudas que los cristianos de Toledo y de su término tuviesen contraídas con los judíos, ya que se encontraban muy empobrecidos por los estragos causados al paso de las tropas mercenarias. Enrique atendió en parte esta petición, concediendo una moratoria de un año en el pago de las deudas, durante el cual tampoco se cobrarían intereses.

Por otra petición le solicitaban que mandase derribar la cerca de la judería «que es començada a faser, por quanto la nunca y ovo et se

\footnotetext{
${ }^{34}$ AMT, cajón $9 .^{\circ}$, leg. $1 .^{\circ}$, n. 12 (pieza 1), fols. CLXXV-CLXXVIV. IzQUIERdo Benito, R., Privilegios..., op. cit., doc. n..$^{\circ} 84$.

35 León Tello, P., op. cit., I, doc. 33.

${ }^{35}$ AMT, cajón $8 .^{\circ}$, leg. $1 .^{\circ}$, n. ${ }^{\circ}$ 9. IzQuierdo Benito, R., Privilegios..., op. cit., doc. n. ${ }^{\circ} 85$.

37 Para mayores detalles vid. nuestro estudio "Aspectos de Toledo y su comarca durante la crisis de la segunda mitad del siglo XIV", en Provincia, revista de la Diputación de Toledo, n. ${ }^{\circ} 105,1978$, s/pág.
} 
apoderan de la villa». Sin embargo, no mandó que se derribase, sino que encargó al arzobispo don Gome Manrique que inspeccionase la obra y mandase abrir los portillos que considerase oportunos ${ }^{38}$.

En 1367, aun no siendo todavía rey legítimo, Enrique celebró Cortes en Burgos en las que, el 15 de febrero se promulgó un ordenamiento a solicitud de los procuradores de Toledo, en el cual las peticiones eran semejantes a las anteriores ${ }^{39}$. Entre ellas, nuevamente le pedian que suprimiese parte de las deudas que los de Toledo y su término tenían contraídas con judíos, "por quanto están muy estroydos et an levado los judíos dellos grandes quantías de maravedis... lo qual fesieron con esfuerço de don Samuel el Levi que eran grand privado de aquel tirano que se llamava rey». Les contestó que se cumpliese lo que, con carácter general para todo el reino, ya se había acordado en aquellas mismas Cortes.

Pero el acontecimiento que iba a agravar la situación de la ciudad, en general, y de la comunidad judía, en particular, fue el asedio impuesto a Toledo por Enrique de Trastámara, una vez retornado a Castilla tras la derrota de Nájera, y que duró desde abril de 1368 a mayo de 1369, cuando la ciudad se rindió tras la muerte de Pedro I en Montiel ${ }^{40}$. Toledo se convirtió en uno de los bastiones más firmemente partidarios del rey don Pedro, el defensor de los judíos, y éstos, una vez más, iban a ser las principales víctimas. Al mes siguiente de su entrada en la ciudad, el nuevo rey exigió a la aljama de Toledo el pago de una sanción de 20.000 doblas de oro, que tendrían que ser pagadas con prontitud, por lo que se decretó que fuesen vendidos en pública almoneda, no solamente los bienes muebles y raíces de los judíos, sino hasta los cuerpos de éstos si fuese preciso. Es decir, que se decretaba su venta como esclavos. Se desconoce el verdadero alcance que esta drástica medida tuvo, pero,

${ }_{38}$ Aunque se ha solido considerar que esta cerca era la de la judería, que se estaría reparando, nosotros pensamos que se trata de una nueva, que posiblemente pretendiese proteger al barrio de la Alacava que fue el que verdaderamente sufrió los estragos del saqueo del año 1355, para así evitar situaciones parecidas en el futuro. En el documento se indica que esa cerca nunca había existido ( $p$ por quanto la nunca y ovo») y la de la judería ya llevaba varios siglos levantada. Por eso, parece tratarse de una nueva construcción, pues pensamos que era absurdo pretender engañar a Enrique de Trastámara diciéndole que la judería nunca había estado cercada, cuando él mismo la habría visto.

${ }^{39}$ AMT, cajón $8^{\circ}$, leg. $1^{\circ}, \mathrm{n} .^{\circ} 10$ (pieza 2). Cortes de los antiguos reinos de León y Castilla, publicadas por la Real Academia de la Historia, t. Il. Madrid 1861, págs. 156-163. IzQUIERDO BentTo, R., Privilegios..., op. cit., doc. n. ${ }^{\circ} 87$.

40 La dramática situación que se debió de vivir en Toledo durante aquel tiempo ha quedado recogida por López de Ayala, Pedro, Crónica del rey don Pedro, Biblioteca de Autores Españoles, t. LXVI. Madrid 1953, pág. 589. 
evidentemente, aunque no se llegasen a vender judíos, debió de contribuir a empobrecer todavía más a la aljama toledana.

No obstante, a pesar del acusado antisemitismo con que se presentaba el nuevo régimen trastamarista -y que tantas adhesiones le debió de suponer-, Enrique II pronto tuvo que empezar a dar marcha atrás, no atendiendo a todas las peticiones que se le hacían contra los judíos pues, en definitiva, al igual que sus antecesores, también los iba a necesitar.

Tras los desastres pasados, la judería toledana empezaría lentamente a recuperarse ${ }^{41}$. Algunos judíos que habían huido regresarían y se reiniciaría la actividad en las tiendas y talleres que tenían dispersos por la ciudad. Significativamente, como ha señalado Pilar León Tello, no hay ni un solo documento de prestamistas judíos en Toledo durante el reinado de Enrique II; la mayoría estaban dedicados al campo o a la recaudación y arrendamiento de rentas ${ }^{42}$.

Sin embargo, la tranquilidad no iba a durar muchos años pues la judería toledana también se vio afectada por los graves movimientos antisemitas que tuvieron lugar en 1391. Al tener conocimiento de las alteraciones andaluzas, la aljama de Toledo, bajo la protección del arzobispo don Pedro Tenorio, acudió a presentar sus temores ante las Cortes que se encontraban reunidas en Madrid. A pesar de todo, en el verano de aquel año, la judería fue asaltada y robada ${ }^{43}$, aunque no sepamos el auténtico alcance demográfico del desastre ${ }^{44}$. Sin embargo, posiblemente fue rîayor el número de los judíos que, conscientes de lo que se avecinaba, optaron por convertirse al cristianismo, cambiándose también sus propios nombres originarios ${ }^{45}$.

41 Según J. VALDEÓN (op. cit, pág. 131), aunque siguieron participando en las tareas financieras de la región, lo cierto es que los judíos toledanos tropezaban con múltiples obstáculos, eran apremiados a la entrega de las sumas que exigía la hacienda regia y, al menor fallo, se les conducía a prisión.

42 León Tello, P., op. cit., I, pág. 161.

43 Enrique III, como castigo, impuso una multa de 30.000 doblas de oro, a pagar en tres plazos, entre todos los que habían participado en el asalto y robos de la judería toledana y a los que también habían comprado cosas de lo robado, para lo que primeramente se realizó una pesquisa para conocer quiénes eran, tanto de la propia ciudad como de otros lugares. AHN, clero, pergaminos, carpeta 3.076, n. ${ }^{\circ}$ 14. Lé́N TelLo, P., op. cit., l, doc. 44.

${ }_{44}$ La fuente hebrea más completa relativa a estos sucesos es la «Elegía a los mártires de Toledo en $1391 \%$, aunque solamente se refiere a las víctimas más destacadas. LEón TELLO, P., op. cit., I, págs. 175-176.

45 Esto se puede comprobar en los libros de cuentas conservados en el Archivo de Obra y Fábrica de la Catedral - serie «Libros del Refitor»-, en los que se recogen los bienes pertenecientes al cabildo y quiénes los tenían arrendados. Así, algunos judíos que antes de 1391 tenían algún bien arrendado, a partir de esa fecha aparecen con un nombre distinto, «cristianizado", y con la palabra "converso» al margen. 
Al cambiar de religión dejaban de pagar los tributos que, hasta entonces, como judíos, habían pagado. De esta manera, entre las muertes ocasionadas y las conversiones, disminuyó considerablemente el número de individuos sujetos a pechos y, por ende, el monto de los ingresos para la hacienda regia. De igual forma, se vieron perjudicados aquellos individuos o instituciones que, por concesión real, tenían situadas determinadas rentas sobre los tributos de las aljamas. Así le ocurrió, por ejemplo, al convento toledano de la Sisla, que tenía asignados, por Juan I, para el cumplimiento de tres capellanías, 4.500 maravedíes en la cabeza del pecho de los judíos de Toledo y no los podía cobrar pues, alegaba, los judíos habían sido robados. Por lo cual solicitó de Enrique III, y éste accedió el 12 de abril de 1397, situar dicha cantidad en otras rentas más seguras (las tercias del arciprestazgo de Canales) ${ }^{46}$.

Desde entonces se iba a iniciar el fenómeno de los conversos, cuyo número iría en aumento, aunque aquellas conversiones, forzadas y oportunistas en muchos casos, iban a ser motivo de nuevos problemas ante las sospechas y recelos que despertaron entre la población cristiana que se resistía a aceptarlos entre ella en igualdad de condiciones. Desde entonces, y a lo largo del siglo siguiente, gran parte del sentimiento popular antisemita se orientó hacia ellos y fueron las principales víctimas de nuevos actos violentos.

Durante el siglo xv se mantendrá un goteo persistente de medidas antijudías, tanto a nivel del reino castellano (disposiciones de Cortes, leyes de Ayllón, pragmática de 1443, etc.), como de la Iglesia (bulas papales), así como de la propia ciudad de Toledo, aunque en el caso toledano no desembocaron en nuevos saqueos y matanzas, al menos por lo que respecta a los judíos que se mantuvieron fieles a su religión.

El barrio judío toledano y sus anejos vieron considerablemente mermada su población, y muchas de sus viviendas, entonces vacías, pasaron a manos de cristianos que las adçuirieron. De esta manera, la zona de tradicional asentamiento de los judíos, estaba cada vez más ocupada por cristianos, algunos de los cuales serían conversos.

En algunas disposiciones de las Ordenanzas de Toledo que se promulgaron a fines del siglo XIV y a comienzos del $\mathrm{XV}$, y que estuvieron en vigor a lo largo de toda esta centuria, en las limitaciones que se impusieron a toda la población en la venta y compra de algunos productos, sobre todo para que no se comprasen antes de una determinada hora y

46 AHN, clero, pergaminos, carpeta 2.964, n. ${ }^{\circ}$ 8. León TelLo, P., op. cit., I, doc. 41. 
así evitar acaparaciones y abusos, se hacía especial hincapié en los judíos y los moros, hacia los cuales, conjuntamente, irán dirigidas varias disposiciones a lo largo del siglo xv.

También, según estas mismas Ordenanzas, estaba prohibido que nadie metiese ni vendiese pescado de río en la judería los miércoles, jueves o viernes de cada semana y en la «quaresma o en los quatro temporas o en las vegillas de los santos que son de ayuno" ${ }^{47}$.

Igualmente estaba prohibido que los cristianos comprasen carne para compartirla y comerla con judío o moro ${ }^{48}$.

En el verano de 1411 San Vicente Ferrer estuvo predicando en Toledo aunque no se conoce el auténtico alcance que sus esfuerzos de convicción pudieron haber tenido entre los judíos toledanos ${ }^{49}$. Cuando al año siguiente se promulgó el Ordenamiento de Ayllón en el que se recogían 23 disposiciones contra los judíos castellanos, el regente don Fernando de Antequera escribió a Toledo indicando que no se aplicase hasta que él no hubiese analizado esas leyes.

En aquel contexto, la comunidad judía toledana, sin dirigentes de relevancia ni intelectuales destacados, se veía relegada por la comunidad conversa, cada vez más numerosa, rica e influyente. Sin embargo, en los años siguientes los conversos toledanos iban a ser las principales víctimas de varios sucesos que, al socaire de la situación política castellana del momento, tuvieron a la ciudad por escenario (rebelión de Pero Sarmiento, revuelta de 1467 , etc.) ${ }^{50}$. De los judíos propiamente dichos _-posiblemente cada vez menos numerosos a juzgar por los repartimientos fiscales ${ }^{51}$ - no se tienen excesivas noticias de esos años de mediados del siglo $\mathrm{xV}$, en su relación con los cristianos. De los que formaban parte de las aproximadamente 300

47 AMT, alacena $2 .^{\circ}$, leg. $6 .^{\circ}, n .{ }^{\circ} 4$, fol. $\mathrm{XL}$.

48 Idem, fols. XCV-XCVI.

49 Según Francisco de PISA [Descripción de la Imperial Ciudad de Toledo y historia de sus antigüedades y grandezas... Toledo 1605 (ed. facsímil del IPIET, pág. 202v)] un grupo de seguidores de San Vicente Ferrer, armados, se dirigieron a la judería y tomaron a la fuerza la actual sinagoga de Santa María la Blanca. Sin embargo, Francisco CanTERA Burgos (Sinagogas españolas. Madrid 1984, págs. 58-59) piensa que todo ello es una leyenda sin ningún fundamento histórico.

50 Para todo lo relacionado con estos acontecimientos vid. BENITO RuANO, Eloy, Toledo en el siglo XV. Madrid 1961. CSIC.

${ }_{51}$ En el repartimiento fiscal de 1439 la aljama toledana pagó 7.000 maravedís, mientras que en el de 1464 y años sucesivos, la cantidad se redujo a 3.500 , signo de un evidente descenso demográfico, aunque sea muy difícil evaluarlo. CARRETE PARRONDO, Carlos, "Tributación económica de las comunidades judías toledanas", en IV Congreso Internacional de las Tres Cuituras. Toledo 1988, págs. 19-34. 
familias establecidas entonces en la ciudad, muy pocos eran los que se dedicaban a su otrora actividad primordial: la usura. Incluso, algunos aparecen como deudores. Sin embargo, sí continuaban arrendando rentas de la catedral ${ }^{52}$. También, como había sido habitual, se seguían dedicando a las más diversas profesiones, en cuyo desempeño mantendrían evidentes contactos con el sector cristiano, hacia el cual, aquéllas, en gran medida, se orientaban.

Una actividad a la que se debieron de dedicar bastantes judíos fue la medicina, aunque posiblemente de una manera un tanto descontrolada, ya que, en una fecha que desconocemos, se difundió por Toledo un pregón en el que se indicaba "como muchos judíos han venido a esa Çibdad de fuera parte a husar de fisicos e otros asaz están en esta dicha Çibdad, e de poco acá han usado e usan del dicho ofiçio de fisicos syn ser examinados... lo qual es muy grand danno delas personas a quien curan"». Por lo cual se mandó que todos los judíos médicos, tanto los que ya estaban en la ciudad como los que se habían establecido recientemente en ella, no practicasen su oficio sin ser antes examinados «por las personas que la dicha çibdad tiene nonbradas para ello». Iguales medidas se aplicaban a los boticarios, que muy probablemente también serían judíos ${ }^{53}$.

Durante el reinado de Juan II, posiblemente en 1451, el Ayuntamiento de Toledo promulgó unas ordenanzas contra los moros y los judíos de la ciudad y de su término, imponiéndoles una serie de medidas restrictivas, como, entre otras, la prohibición de andar de noche por las calles, el entrar en iglesias o monasterios sin autorización, el salir de sus casas durante las festividades cristianas, así como la obligación de llevar señales distintivas cosidas en sus ropas ${ }^{54}$. Ante lo cual, los judíos de Toledo se quejaron al rey ya que éste, en 1450 había dado una orden para que se revocasen y anulasen todas las ordenanzas antijudias que en el reino castellano se hubiesen establecido, pues habían sido muchos los lugares que lo habían hecho, y los judíos se marchaban de aquél. El rey mandó que el Ayuntamiento de Toledo la cumpliese y éste, reunido el 23 de febrero de 1452, revisó las ordenanzas, suprimiendo algunas, pero modificando y manteniendo otras ${ }^{55}$.

52 León Tello, P., op. cit., I, págs. 219-233.

53 AMT, alacena 2. ${ }^{\text {a }}$, cajón $6 .^{\mathrm{a}}, \mathrm{n}^{\circ}$ 2, fols. $143-143 \mathrm{v}$. A los que no lo cumpliesen se les castigaba con una multa de 5.000 maravedís para el reparo de la muralla de la ciudad.

54 Posiblemente, estas ordenanzas sean las que, sin fecha precisa, se conservan en un manuscrito del siglo xvılı, en la Biblioteca Nacional, ms. 1.290, fol. 250. Recopiladas por LEón TELLO, P., op. cit., II, doc. 854.

55 AMT, cajón $5 .^{\circ}$ leg. $7 .^{\circ}, n .^{\circ}$ 2. León Tello, P., op. cit., I, doc. 54. 
Hacia 1459, una antigua sinagoga de la colación de Santo Tomé que llevaba 40 años abandonada, tras el retroceso demográfico que entonces se produjo («quando en aquel barrio moravan judios»), empezó de nuevo a ser utilizada por los judíos como lugar de oración. En aquellos momentos la sinagoga estaba ya rodeada por edificios ocupados por cristianos, los cuales se dirigieron a Enrique IV para que no lo consintiese y éste, el 9 de febrero de 1460, mandó una carta al Ayuntamiento para que prohibiese a los judíos que utilizasen la sinagoga como lugar de reunión, aunque continuase siendo de su propiedad ${ }^{56}$.

Las sucesivas disposiciones que, desde hacía incluso siglos, se habian promulgado para que los judíos llevasen señales distintivas en sus ropas no se debían de cumplir, ya que el 29 de julio de 1475 se difundió un pregón por Toledo en el que se mandaba «que los moros trayan sus capuzes con sus lanas vestidos e los judíos sus sennales», so pena de perder la ropa ${ }^{57}$. Igual medida, entre otras, se acordaron al año siguiente en las Cortes de Madrigal para todo el reino castellano.

En la catedral, la capilla denominada del rey don Sancho o de la Santa Cruz, tenía el derecho a percibir una cantidad sobre toda la carne que se vendiese en Toledo, lo que solía repercutir en el precio de la misma y fue motivo de múltiples quejas para que se suprimiese, aunque nunca se consiguió, ya que los reyes no querían anular una disposición de uno de sus antecesores. De ahí que, a veces, algunos cristianos compraban, a bajo precio, los despojos de la carne de las carnicerías de los judíos, con las consiguientes quejas de los capellanes de dicha capilla, que se consideraban perjudicados al disminuir sus ingresos. Se quejaron ante los Reyes Católicos y éstos, el 27 de enero de 1480 enviaron una provisión a Toledo mandando que ningún cristiano comprase carne en la carnicería de los judios, ni los judíos la vendiesen a los cristianos, pue ello iba en detrimento de los derechos de la citada capilla ${ }^{58}$.

Poco después, el 24 de febrero, se pregonó por la ciudad cómo «muchos de los cristianos vesinos desta dicha çibdad, contra sus conçiençias e animas, van a conprar carne a las carniçerías de los judíos e moros, e por quanto esto se a defendido por nuestra santa fee e mandamientos della", se mandaba que ningún cristianos cristiano, en adelante, fuese osado de ir a comprar carnes a dichas carnicerías ${ }^{59}$.

56 Idem, cajón $5 .^{\circ}$, leg. $2{ }^{\circ}$, n. ${ }^{\circ} 6.1$ dem, doc. 57.

Idem, alacena $2 .^{\text {a }}$, leg. $6 .^{\circ}, \mathrm{n} .^{\circ} 2$, fol. $86 \mathrm{v}$.

58 SuÁREZ FeRnández, Luis, Documentos acerca de la expulsión de los judíos. Valiadolid 1964, págs. 166-167.

${ }_{59}$ AMT, alacena $2 .^{\text {a }}$, leg. $6 .^{\circ}, \mathrm{n}^{\circ} 2$, fols. $83 \mathrm{v}-84$. Las penas eran de 300 maravedís la primera 
En las Cortes reunidas en Toledo aquel año de 1480, se acordó, como ya se había hecho en las de Valladolid de 1411 y que no se había cumplido, que en un plazo de dos años, los judíos habrían de integrarse en barrios separados de los cristianos, rodeados por una cerca. Esta medida no tendría una excesiva aplicación en Toledo, donde siempre los judíos habían tenido su barrio propio, limitado por una muralla, aunque en aquellos momentos muchos edificios se encontrasen vacíos ante el retroceso poblacional. Lo único que pudo haber supuesto es que aquellos judíos que vivían en otras zonas de la ciudad, tuviesen que asentarse en la judería.

El 8 de febrero de 1483, a petición del Ayuntamiento de Toledo, que se quejó de que en la ciudad, tanto los cristianos como los moros y judíos trabajaban los domingos, los Reyes Católicos mandaron que se cumpliese la disposición que en 1387 se había acordado en las Cortes de Briviesca, prohibiendo que nadie trabajase en domingo ni en días festivos, y que en esos días los moros y los judíos no trabajasen en público ni en lugares donde se les pudiese ver y oír ${ }^{60}$.

En este ambiente de continuas disposiciones antijudías, en 1485 se estableció en Toledo el Tribunal de la Inquisición. Aunque no se dirigía directamente contra los judíos sino contra los conversos que judaizaban, los inquisidores obligaron a los rabinos, bajo juramento, que ordenasen a los judíos a que cienunciasen a los herejes ante el Tribunal del Santo Oficio ${ }^{61}$. Era frecuente que en los procesos apareciesen judíos como testigos.

Es posible que, ante el temor a ser llamados por la Inquisición, algunos judíos se refugiasen en tierras de señorío, donde podían encontrarse más a resguardo de las pesquisas. Para los toledanos, Maqueda, que entonces contaba con una judería numéricamente mayor a la de la capital, pudo haber sido un lugar de refugio ${ }^{62}$.

Los días de la ruptura definitiva y de la expulsión estaban cercanos.

\section{CONCLUSIÓN}

Como se puede comprobar a través de las líneas precedentes, la historia de los judíos de Toledo y sus relaciones con el sector cristiano de

\footnotetext{
vez, 600 la segunda y por la tercera, si fuese «persona honrrada", pagaría 1.200 y si fuese «de vaxa suerte», le darían 50 azotes públicamente por la ciudad. En iguales penas incurrirían los carniceros moros o judíos que vendiesen carne a los cristianos.

${ }^{60}$ Idem, cajón $8 .^{\circ}$, leg. $1 .^{\circ}$, n. ${ }^{\circ} 24$.

LEÓN TELLO, P., op. cit., , I, pág. 255.

62 Idem, «La expulsión de los judíos», en Anales Toledanos, XXI, 1985, págs. 54-55.
} 
la ciudad, está llena de claroscuros, es decir, de momentos de cierta tranquilidad en esa convivencia, alternados con otros de drásticos enfrentamientos. Si los siglos XII y XIII fueron una etapa en la que las relaciones se mantuvieron relativamente pacíficas, en los dos siglos siguientes éstas se alteraron de una manera acusada, rompiendo el inestable equilibrio que hasta entonces se había mantenido.

Los contactos entre judíos y cristianos se habían basado casi exclusivamente en unos intereses económicos, preferentemente relacionados con los préstamos, en los que el sector cristiano acabó endeudado con el judío. Aquella situación era muy difícil que se pudiese mantener inalterable durante mucho tiempo y de ahí las constantes peticiones que se realizaron en Cortes para restringir o anular las deudas, aunque poca efectividad llegaron a tener.

Sin embargo, el auténtico detonante que desequilibró definitivamente aquellas relaciones, fue la crisis económica del siglo XIV y el conflicto dinástico que también entonces se desarrolló. A partir de aquel momento, la comunidad judía toledana, cada vez más reducida - muertes, huidas, conversiones - se vio sometida a una serie de disposiciones que tendieron a acentuar su estado de segregación y que terminaron por desembocar en la ruptura definitiva de 1492.

Este panorama, escuetamente presentado a modo de síntesis, dimanado del análisis de un ámbito concreto como era la ciudad de Toledo - a pesar de la específica peculiaridad y significado de su judería-, puede, con algunos evidentes matices, tomarse como modelo de referencia para conocer cual fue la situación de los judíos castellanos, en general, en su relación con el sector cristiano dominante, a lo largo de la Edad Media. Evidentemente, para el caso toledano y, por tanto, también para el castellano, puede resultar un tanto arriesgado admitir que existió una auténtica convivencia, al menos en el sentido de cofraternidad que este término debe de llevar implícito. 